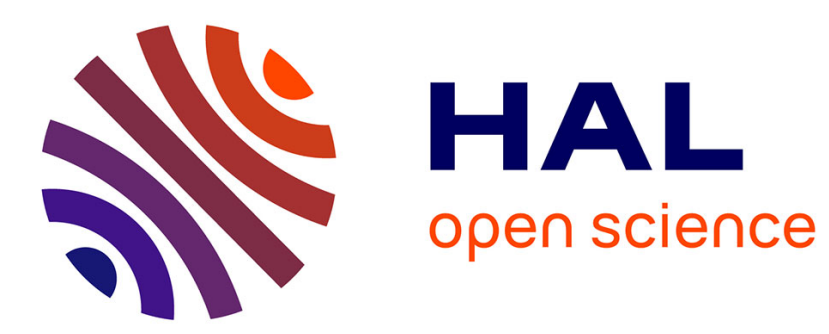

\title{
Magnetic Property and Evaluation of MnZn-Ferrite Fine Particles in Langmuir Blodgett Film
}

T. Oku, M. Ohwada, T. Sato, E. Ohta

\section{To cite this version:}

T. Oku, M. Ohwada, T. Sato, E. Ohta. Magnetic Property and Evaluation of MnZn-Ferrite Fine Particles in Langmuir Blodgett Film. Journal de Physique IV Proceedings, 1997, 07 (C1), pp.C1-529C1-530. 10.1051/jp4:19971216 . jpa-00254868

\section{HAL Id: jpa-00254868 https://hal.science/jpa-00254868}

Submitted on 1 Jan 1997

HAL is a multi-disciplinary open access archive for the deposit and dissemination of scientific research documents, whether they are published or not. The documents may come from teaching and research institutions in France or abroad, or from public or private research centers.
L'archive ouverte pluridisciplinaire HAL, est destinée au dépôt et à la diffusion de documents scientifiques de niveau recherche, publiés ou non, émanant des établissements d'enseignement et de recherche français ou étrangers, des laboratoires publics ou privés. 


\title{
Magnetic Property and Evaluation of MnZn-Ferrite Fine Particles in Langmuir Blodgett Film
}

\author{
T. Oku, M. Ohwada, T. Sato and E. Ohta \\ Department of Materials Science, Keio University, 3-14-1, Hiyoshi, Kohoku-ku, Yokohama, Kanagawa, \\ 223 Japan
}

\begin{abstract}
We investigated the magnetic properties of thin film samples with different number of layers stacked by the LB technique. The film samples showed a magnetically complex behavior in low temperature region, which is insufficiently explained by the idea of the homogenous dipole interaction field analogous to the demagnetizing field. The film thickness dependent behavior is discussed in terms of a picture of the magnetic viscosity which is realized in reentrant spin glass materials.
\end{abstract}

\section{INTRODUCTION}

The magnetic nature of a system consisting of single domain magnetic particles is described in terms of the intraparticle anisotropy and the interparticle dipole interaction. If the degree of the interparticle interaction energy is comparable with that of the intraparticle anisotropy, the system exhibits magnetically complex behavior which is strongly dependent on the arrangement of particles. A thin film sample consisting of particles shows magnetically anisotropic behavior. Such behavior in the superparamagnetic region was well described by J.L. Dormann et al. [1]. According to their study, the magnetization $M$ of a system consisting of particles whose easy axes are randomly distributed is expressed as follows:

$$
M=\left\langle\mu^{2}>H_{\text {eff }} / 3 \mathrm{kB}\left(\mathrm{T}-\theta_{\mathrm{sp}}\right)<\mathrm{V}\right\rangle,
$$

where $<>$ denotes the average over all particles, $\mu$ is the moment of particles, $H_{\text {eff }}$ the effective magnetic field, $V$ the volume of particles, and $\theta_{s p}$ the characteristic temperature analogous to the Curie temperature in ferromagnetic materials. Here, since the dipole interaction can be expressed via the Lorentz field, $H_{e f f}=N_{i} M-N_{e} M$ where $N_{i}$ and $N_{e}$ are the demagnetizing factor relevant to the particle and the global exterior shapes of the sample, respectively. In the case of thin particle film sample, $\mathrm{N}_{\mathrm{e}} \approx 0$ and 1 for applied fields $\mathrm{H}_{\mathrm{app}}$ in the direction parallel and perpendicular to the film plane, respectively. On the other hand, the complex magnetic properties in the low temperature region have not been clarified in the same way. By means of the Langmuir-Blodgett (LB) technique, we can obtain the two-dimensionally arranged particles in the film-like shape and change its thickness in a unit of a particle mean diameter. In this paper, we investigated the magnetic properties of particle films with different number of layers stacked by the LB technique.

\section{EXPERIMENTAL}

We prepared a monolayer and several multilayer samples consisting of $\mathrm{MnZn}$-ferrite particles with a mean diameter of $100 \AA$ by the LB technique. The magnetizations, $M_{/}$and $M_{\perp}$, and the temperature dependent magnetic susceptibilities, $\chi / /$ and $\chi \perp$, were obtained in the field applied in the direction parallel and perpendicular to the film plane, respectively.

\section{RESULTS AND DISCUSSION}

From TEM micrographs of plane and cross section of the film, we examined the particle arrangement and determined the film thickness (Fig. 1). The particles are densely and isotropically distributed in the film sample and the film thickness is approximately proportional to the number of stacked layers.

Fig. 2 shows the magnetization curves of the 10-layer sample obtained at $6 \mathrm{~K}$. The initial susceptibility $\chi_{i}$ and remanent magnetization $M_{R}$ in $M_{/ /}$are larger than those in $M \perp$. This anisotropic behavior can be explained in terms of the idea of demagnetizing effect of interparticle dipole interaction. The peak temperature $T_{g}$ in $\chi_{/ /}$under the zero-fieldcooled condition is lower than that in $\chi \perp$ (Fig.3). This difference between $\mathrm{T}_{\mathrm{g} / /}$ and $\mathrm{T}_{\mathrm{g}} \perp$ is explained on the basis of the 


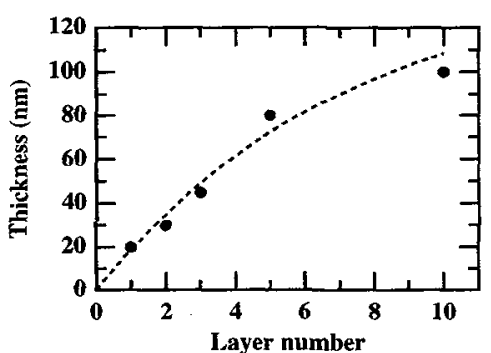

Fig.1 Film thickness vs layer number

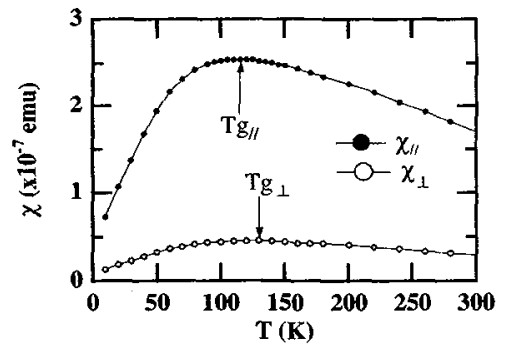

Fig.3 Temperature dependence of susceptibilities

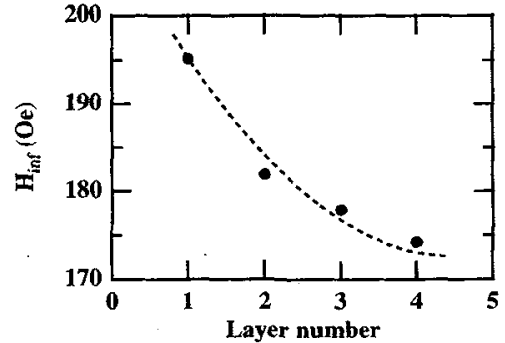

Fig. $5 \mathrm{H}_{\text {inf }}$ vs layer number

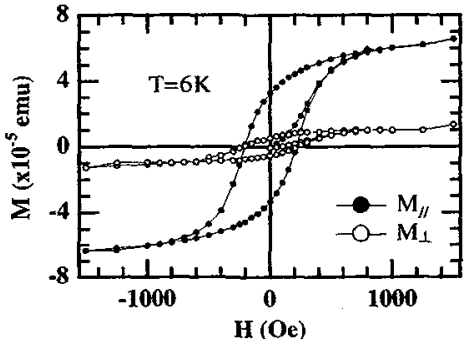

Fig.2 Magnetization curves

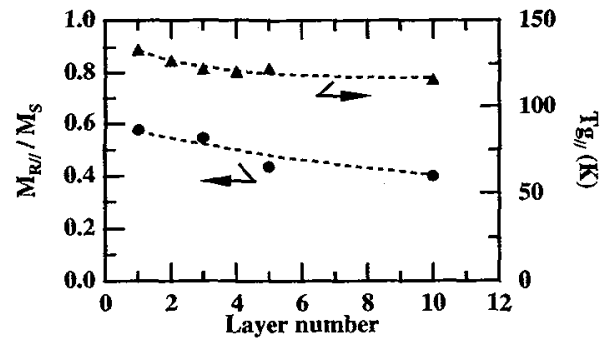

Fig.4 $\mathrm{M}_{\mathrm{R}} / \mathrm{MS}_{\mathrm{S}}$ and $\mathrm{Tg}$ vs layer number, where MS is saturation magnetization.

difference between the characteristic temperatures $\boldsymbol{\theta}_{\mathrm{sp}}$ :

$$
\left.\theta_{\mathrm{sp}}=\left\langle\mu^{2}\right\rangle\left(\mathrm{N}_{\mathrm{e}}-\mathrm{N}_{\mathrm{i}}\right) / 3 \mathrm{k}_{\mathrm{B}}<\mathrm{V}\right\rangle,
$$

in fields applied parallel $\left(\mathrm{N}_{\mathrm{e}} \approx 0\right)$ and perpendicular $\left(\mathrm{N}_{\mathrm{e}} \approx 1\right)$ to the film plane. Such magnetically anisotropic properties are observed for all of our film samples.

Next, we show the layer number dependence of $\mathrm{M}_{\mathrm{R}} / / \mathrm{T}_{\mathrm{g}} / /$ (Fig.4) and the inflection point field in initial magnetization process, $\mathrm{H}_{\mathrm{inf}}$ (Fig.5). The decrease in $\mathrm{MR}_{\mathrm{R}}, \mathrm{T}_{\mathrm{g} / /}$ and $\mathrm{H}_{\text {inf }}$ with increasing the layer number cannot be explained by the idea of the homogeneous demagnetizing field, i.e., the mean-field-like treatment of the dipole interaction. Thus, the filmthickness dependent behavior should be explained based on the inhomogeneous filed picture. We tentatively utilize the idea of the magnetic viscosity originating from the competing magnetic interaction analogous to that in reentrant spin glass (RSG) materials [2] as follows: In a thin film, the direction of a magnetic moment should be restricted in the film plane due to the large demagnetizing field in the direction perpendicular to a film plane. This suggests that the motion of magnetic moment is strongly restricted in the film sample by the magnetic viscosity through the competing interparticle interaction. The behavior of $\mathrm{H}_{\text {inf }}$ indicates that such restriction becomes more significant with decreasing the film thickness. In other words, the magnetic viscosity increases as the layer number decreases. Since the increase in magnetic viscosity must cause the increase in $\mathrm{MR}_{\mathrm{R}}$ and $\mathrm{T}_{\mathrm{g}}$, therefore, the present model gives a consistent explanation for the low temperature.

In conclusion, the particle film sample prepared by LB technique shows a complex anisotropic behavior in low temperature region, which is insufficiently explained by the homogeneous demagnetization field. The idea of film thickness dependent magnetic viscosity is useful to explain the low temperature behavior.

[1] Dormann J.L., Fiorani D. and Tronc E., in: Nanophase Materials, Synthesis, Properties, Applications, Eds. G.C. Hadjipanayis and R.W. Siegel (Nato ASI Series E, 260, Kluwer Acad. Publ., Dordrecht, 1994) p. 635-644.

[2] Mituda S., Yoshizawa H., Watanabe T., Itoh S., Endoh Y. and Mirebeau I., J. Phys. Soc. Jpn. 60 (1991) $1721-1729$. 